\title{
Reduction of Endotracheal Tube Connector Dead Space Improves Ventilation: A Bench Test on a Model Lung Simulating an Extremely Low Birth Weight Neonate
}

\author{
Vadim A Ivanov MD
}

\begin{abstract}
BACKGROUND: The reduction of instrumental dead space is a recognized approach to preventing ventilation-induced lung injury in premature infants. However, there are no published data regarding the effectiveness of instrumental dead-space reduction in endotracheal tube (ETT) connectors. We tested the impact of the Y-piece/ETT connector pairs with reduced instrumental dead space on $\mathrm{CO}_{2}$ elimination in a model of the premature neonate lung. METHODS: The standard ETT connector was compared with a low-dead-space ETT connector and with a standard connector equipped with an insert. We compared the setups by measuring the $\mathrm{CO}_{2}$ elimination rate in an artificial lung ventilated via the connectors. The lung was connected to a ventilator via a standard circuit, a 2.5-mm ETT, and one of the connectors under investigation. The ventilator was run in volume-controlled continuous mandatory ventilation mode. RESULTS: The low-dead-space ETT connector/Y-piece and insert-equipped standard connector/Y-piece pairs had instrumental dead space reduced by 36 and $67 \%$, respectively. With set tidal volumes $\left(\mathrm{V}_{\mathrm{T}}\right)$ of $2.5,5$, and $10 \mathrm{~mL}$, in comparison with the standard ETT connector, the low-dead-space connector reduced $\mathrm{CO}_{2}$ elimination time by $4.5 \%(P<.05), 4.4 \%(P<.01)$, and $7.1 \%$ (not significant), respectively. The insert-equipped standard connector reduced $\mathrm{CO}_{2}$ elimination time by 13.5, 25.1, and 16.1\% (all $P<.01$ ). The low-dead-space connector increased inspiratory resistance by $17.8 \%(P<.01), 9.6 \%(P<.05)$, and $5.0 \%$ (not significant); the insert-equipped standard connector increased inspiratory resistance by 9.1, 8.4, and 5.9\% (all not significant). The low-dead-space connector decreased expiratory resistance by $6.8 \%(P<.01)$ and $1.8 \%$ (not significant) and increased it by $1.4 \%$ (not significant); the insert-equipped standard connector decreased expiratory resistance by 1.5 and $1 \%$ and increased it by $1 \%$ (all not significant). The low-dead-space connector increased work of breathing by $4.7 \%(P<.01), 3.8 \%(P<.01)$, and $2.5 \%$ (not significant); the insert-equipped standard connector increased it by $0.8 \%$ (not significant), $2.5 \%(P<.01)$, and $2.8 \%(P<.01)$. CONCLUSIONS: Both methods of instrumental dead-space reduction led to improvements in artificial lung ventilation. Negative effects on resistance and work of breathing appeared minimal. Further testing in vivo should be performed to confirm the lung model results and, if successful, translated into clinical practice. Key words: ventilator-induced lung injury; bronchopulmonary dysplasia; very low birthweight infants; instrumental dead space; endotracheal tube connector. [Respir Care 2016;61(2):155-161. (C) 2016 Daedalus Enterprises]
\end{abstract}

\section{Introduction}

Ventilator-induced lung injury is considered an important causative factor in the pathophysiology of broncho-

Dr Ivanov is affiliated with the Section of Neonatal-Perinatal Medicine, Department of Pediatrics, University of Oklahoma Health Sciences Center, Oklahoma City, Oklahoma.

This paper has been presented in part as a poster at the 2011 meeting of the American Pediatric Society, held April 30 to May 3, 2011, in Denver, Colorado. pulmonary dysplasia (BPD) in premature infants. ${ }^{1}$ Limiting ventilator-associated lung overdistention/damage is a well-recognized approach for the prevention of BPD, but

\footnotetext{
Dr Ivanov has disclosed no conflicts of interest.

Correspondence: Vadim A Ivanov MD, Section of Neonatal-Perinatal Medicine, Department of Pediatrics, University of Oklahoma Health Sciences Center, 1200 N. Everett Drive, ETNP 7504, Oklahoma City, OK 73104. E-mail: vadim-ivanov@ouhsc.edu.
}

DOI: $10.4187 /$ respcare. 04076 
the best means of prevention is yet to be developed. ${ }^{2,3} \mathrm{In}$ extremely premature infants who require ventilation support, the instrumental dead space is relatively large, sometimes at or even exceeding the tidal volume $\left(\mathrm{V}_{\mathrm{T}}\right){ }^{4}{ }^{4} \mathrm{To}$ achieve adequate alveolar ventilation, a clinician must use a higher $\mathrm{V}_{\mathrm{T}}$, which increases the risk of both ventilatorinduced lung injury and BPD as a result of lung overdistention with large $\mathrm{V}_{\mathrm{T}}$ values. Another approach to this problem is to accept higher blood $\mathrm{P}_{\mathrm{CO}_{2}}$ levels, which permits the use of a smaller $\mathrm{V}_{\mathrm{T}}$. This permissive hypercapnia approach has yielded improved BPD rates,, 56 clearly demonstrating that $\mathrm{V}_{\mathrm{T}}$ and/or breathing frequency reduction is a reasonable approach to BPD prevention. However, researchers question whether these higher $\mathrm{P}_{\mathrm{CO}_{2}}$ levels are safe for other organs, especially the brain. ${ }^{7}$

The benefits of reducing instrumental dead space or mitigating its effects are well-recognized and discussed in the literature..$^{8,9}$ Multiple approaches to reduce instrumental dead space and/or its effects on patients have been proposed; ${ }^{3,8-15}$ these suggestions even include using lung assist with extracorporeal $\mathrm{CO}_{2}$ removal. ${ }^{16}$ However, trimming the endotracheal tube (ETT) seems to be the only widely accepted method. ${ }^{17}$ The most recent advance in this field was validation of high frequency oscillator ventilation as a method capable of reducing BPD. ${ }^{18}$

Another simple solution has been proposed: a low-deadspace ETT connector. ${ }^{19}$ However, there is no published research regarding the effects of the low-dead-space connector. In addition, upon examining the connections between the standard endotracheal tube connector and the low-dead-space connector and a Y-piece, the author noted that the Y-piece itself has significant instrumental dead space, which is not eliminated by using the low-deadspace connector. Thus, the author designed an insert to further reduce the instrumental dead space of the entire conduit that is formed by the Y-piece and the ETT connector.

Previous studies have validated the mechanical models for comparing the impact of dead space in different combinations of the respiratory equipment. ${ }^{20,21}$ These models eliminate the uncontrollable variables that are often present in living beings. The model used by Wald et $\mathrm{al}^{21}$ is based on measurement of the $\mathrm{CO}_{2}$ removal rate from a test lung connected to a ventilator with the equipment under the test. Using this model was especially attractive because the model permits the direct measurement of the patientrelevant parameters of the respiratory equipment.

In this study, comparative testing of 3 ETT and Y-piece setups was performed. The setup influence on $\mathrm{CO}_{2}$ elimination time and additional mechanical parameters of the respiratory system, including resistance and work of breathing, was measured for various tidal volumes using the mechanical model.

\section{QUICK LOOK}

\section{Current knowledge}

Positive pressure ventilation in a premature newborn baby is one of the major factors responsible for the ventilator associated trauma leading to development of broncho-pulmonary dysplasia. Reduction in the instrumental dead space improves alveolar ventilation and can reduce the ventilator associated lung trauma.

\section{What this paper contributes to our knowledge}

In a lung model study, reduction of instrumental dead space at the level of the endotracheal tube adaptor results in more efficient ventilation. Changes in airway resistance were small. If confirmed in in vivo experiments, this modification could eventually lead to reduction in incidence and/or severity of broncho-pulmonary dysplasia.

\section{Methods}

This research was exempted from Institutional Review Board review by the University of Oklahoma Institutional Review Board.

I adapted the previously established mechanical model ${ }^{21}$ to simulate the ventilator settings and parameters of a human patient on the lower end of viability, with a body weight of about $500 \mathrm{~g}$. The typical parameters of larger premature infants were also studied. All experiments were performed at room temperature with no warming or humidification equipment or mode used.

\section{Equipment and Setup}

A SERVO-i ventilator (Maquet, Wayne, New Jersey) equipped with an Air Life infant isothermal breathing circuit with a $90^{\circ}$ Y-piece (Cardinal Health, Dublin, Ohio; catalog number MR850) was used in neonatal mode. In order to exclude potential interfering variables, air filters, humidifiers, and warmers were not used. A $46-\mathrm{mL}$ neonatal artificial test lung supplied with the ventilator was connected to the Y-piece of the circuit using a $2.5-\mathrm{mm}$ internal diameter ETT via a $15-\mathrm{mm}$ connector with standard dimensions (both from Portex/Smith Medical, Dublin, Ohio). An extra volume of $1.5 \mathrm{~mL}$ was added between the ETT and the artificial lung to represent the anatomical dead space. The ETT was cut to $13 \mathrm{~cm}$ in length. The exhalation elbow of the circuit had a custom-embedded probe of the $\mathrm{CO}_{2}$ analyzer (Philips Monitor, Andover, Massachusetts). The $\mathrm{CO}_{2}$ analyzer produced a sine wave of $\mathrm{CO}_{2}$ concentration in the exhaled air on the monitor. The 


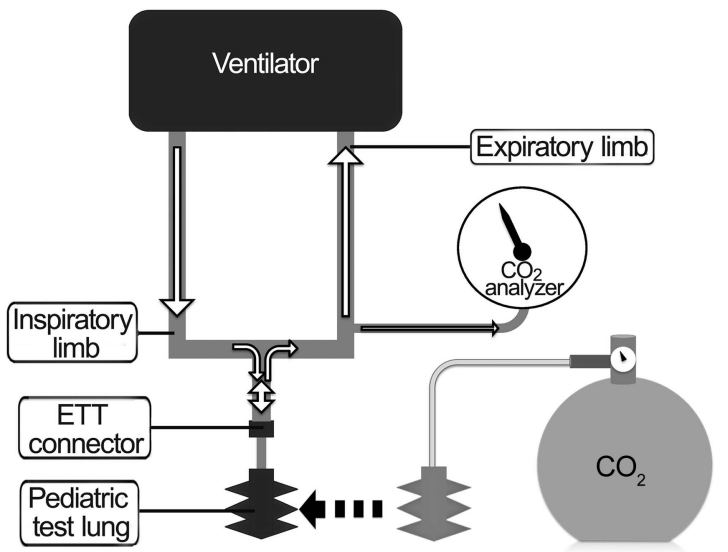

Fig. 1. Schematic of study setup.

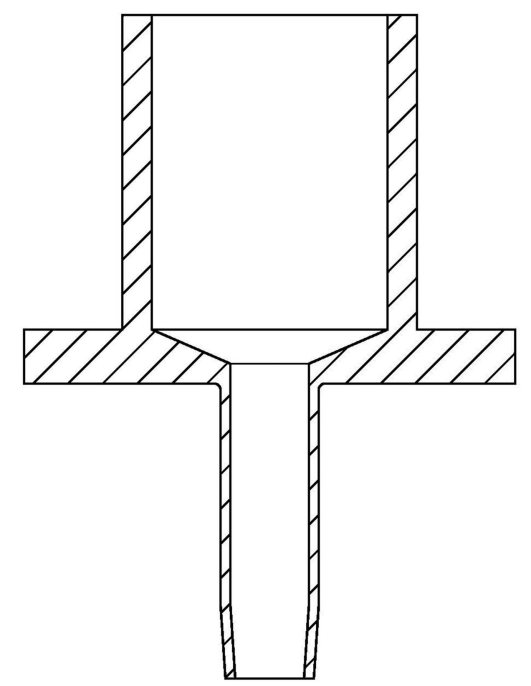

Fig. 2. Standard endotracheal tube connector.

schematic representation of the equipment setup is presented in Figure 1.

The ventilator/circuit was assembled according to the manufacturer's specifications. The full pre-use calibration and testing procedure was performed following the manufacturer's guidelines, as detailed in the user manual. The circuit compliance compensation was enabled. The ventilator was set at the volume-controlled continuous mandatory ventilation mode with PEEP of $5 \mathrm{~cm} \mathrm{H}_{2} \mathrm{O}$, delivering room air at a frequency of 60 breaths/min. Inhalation time was set at $0.5 \mathrm{~s}$ with no inspiratory pause.

The experiment was performed with 3 different connector configurations used to link the Y-piece and the ETT: (1) standard connector that was supplied with the ETT (Fig. 2); (2) low-dead-space connector provided by Hallowell EMC, Pittsfield, Massachusetts (Fig. 3) (the connector is manufactured with a sample port, which was occluded during the experiment); (3) standard connector as supplied with the ETT, but equipped with an insert

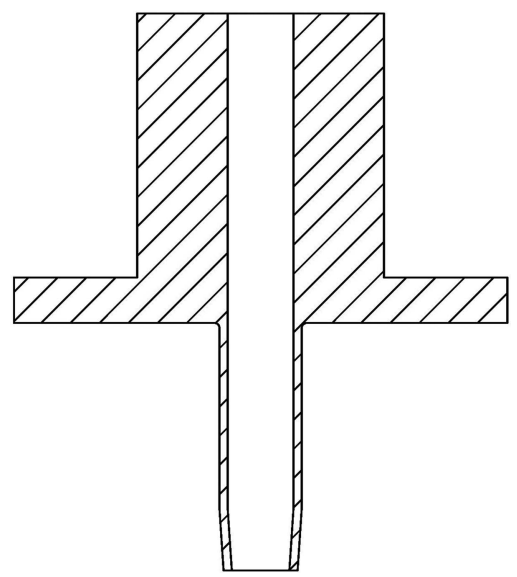

Fig. 3. Low-dead-space endotracheal tube connector.

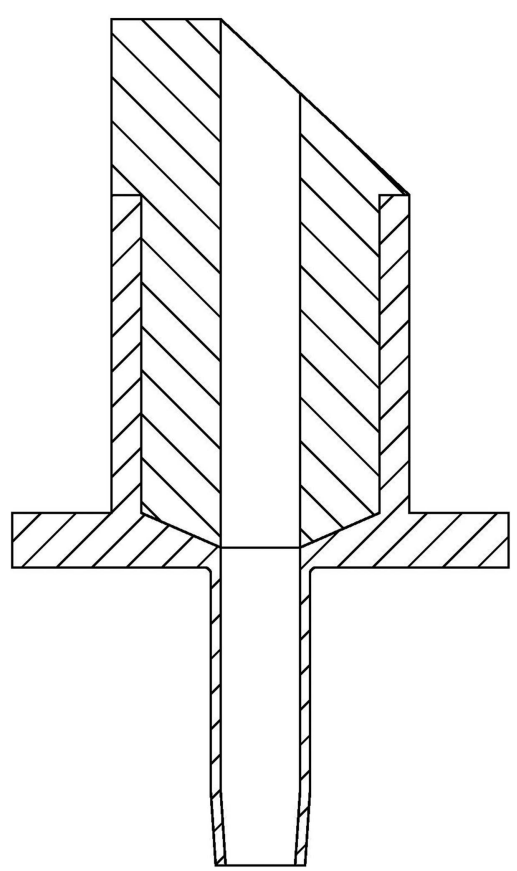

Fig. 4. Standard endotracheal tube connector with insert placed in it.

made of inert plastic with a $2.5-\mathrm{mm}$ internal diameter (Fig. 4). As can be seen in Figure 4, the insert fills the excessive dead space in the standard connector in the same fashion as the low-dead-space connector. The insert also extends into the Y-piece, further reducing its dead space.

The instrumental dead space of the combinations of the Y-piece and the ETT connectors was measured geometrically. The volume of the insert-equipped standard connector was measured by the water displacement method ascribed to Archimedes. ${ }^{22}$ The dead space of the conduit composed of the Y-piece and the standard ETT connector with insert was calculated by subtracting the insert volume 
from the measured dead space of the Y-piece and standard ETT connector combination.

\section{Procedure}

Before the experiment, the ventilator was put in standby mode. The $\mathrm{CO}_{2}$ analyzer was switched on and warmed up for $20 \mathrm{~min}$. Then the artificial lung with its additional anatomical dead space was filled with $100 \% \mathrm{CO}_{2}$ (United States Pharmacopoeia) and immediately attached to the ETT, without any agitation or disturbance. Following attachment of the artificial lung to the ETT, the ventilator was started, and the $\mathrm{CO}_{2}$ analyzer monitor was observed for $\mathrm{CO}_{2}$ concentration sine waves, synchronous with breaths. The time required for complete removal of $\mathrm{CO}_{2}$ was recorded in full seconds, equal to the number of breaths. The complete removal of $\mathrm{CO}_{2}$ out of the test lung was evidenced by a flat line at the zero mark on the monitor. Following observation of the flat line on the $\mathrm{CO}_{2}$ analyzer monitor for $10 \mathrm{~s}$, the artificial lung was manually squeezed several times to move most of the gas out to the lung, thus to ensure the absence of any residual $\mathrm{CO}_{2}$. Each combination of connections was tested 10 times, with $\mathrm{V}_{\mathrm{T}}$ set at $2.5,5$, and $10 \mathrm{~mL}$.

In a separate run under the same conditions, we tested the effect of the connectors on the measured and calculated ventilator parameters. These parameters included endexpiratory pressure, peak airway pressure, end-expiratory flow, dynamic compliance, resistance at inspiration and expiration, and work of breathing. Each combination of connections was tested 10 times (10 breaths), with $\mathrm{V}_{\mathrm{T}}$ set at $2.5,5$, and $10 \mathrm{~mL}$. Room air was used for filling of the test lung and its ventilation. The data were downloaded from the ventilator and analyzed.

Statistical analysis was performed with a one-way analysis of variance test for independent samples with a post hoc Tukey test. The mean values of the 10 runs of each experiment were compared. An $\alpha$ level of $<0.05$ was considered significant. The calculations were performed using an online tool (http://vassarstats.net/anovalu.html, Accessed September 18, 2015).

\section{Results}

The instrumental dead space of the conduit formed by the Y-piece and the ETT connector was measured/calculated as $3.72 \mathrm{~mL}$ for the standard configuration, $2.37 \mathrm{~mL}$ ( $36 \%$ less) for the Y-piece with the low-dead-space connector, and $1.22 \mathrm{~mL}$ (67\% less) for the combination of the Y-piece and standard connector with the insert in place.

The complete elimination of $\mathrm{CO}_{2}$ out of the test lung was confirmed by the absence of any detectable $\mathrm{CO}_{2}$ following a few complete squeezes of the test lung at the end of each experiment. The time required for complete elim-

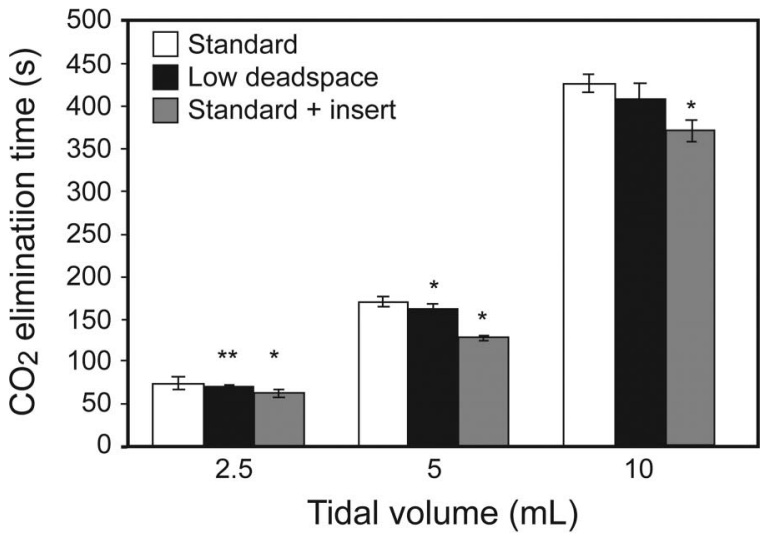

Fig. 5. The time required for complete elimination of $\mathrm{CO}_{2}$ out of the test lung. ${ }^{*}=P<.01$ compared with the standard connector; ${ }^{\star *}=P<.05$ compared with the standard connector. Whiskers denote \pm SD.

ination of $\mathrm{CO}_{2}$ out of the artificial lung is shown in Figure 5. The insert-equipped standard connector reduced the elimination time by $13.5,25.1$, and $16.1 \%$ (all $P<.01$ ), compared with the standard connector alone, as measured with $\mathrm{V}_{\mathrm{T}}$ of $2.5,5$, and $10 \mathrm{~mL}$, respectively. The low-dead-space connector reduced the time by $4.5 \%(P<.05), 4.4 \%$ $(P<.01)$, and $7.1 \%$ (not significant), compared with the standard ETT connector, as measured with $\mathrm{V}_{\mathrm{T}}$ of 2.5, 5, and $10 \mathrm{~mL}$, respectively.

Both the low-dead-space connector and the insertequipped standard connector changed the respiratory mechanics parameters of the system, which are summarized in Table 1. Inspiratory resistance increased but reached statistical significance only with the low-dead-space connector, ventilated with $\mathrm{V}_{\mathrm{T}}$ of 2.5 and $5 \mathrm{~mL}$ (up 17.8 and 9.6\%). However, the corresponding increase of work of breathing was 4.7 and $3.8 \%$, and the increase in dynamic compliance was 8.2 and $10.8 \%$. In contrast, there was a declining trend in the expiratory resistance, which reached statistical significance with the low-dead-space connector, ventilated with $\mathrm{V}_{\mathrm{T}}$ of $2.5 \mathrm{~mL}$ (down $6.8 \%$ ).

\section{Discussion}

This study provides experimental support for the hypothesis that reduction of instrumental dead space leads to improvements in extremely low-birth weight neonate lung bench model ventilation. In practical terms, this means that the same level of alveolar ventilation could be achieved with less minute ventilation with the use of low-deadspace equipment. This reduction in the required minute ventilation allows the clinician to employ less harmful levels of $\mathrm{V}_{\mathrm{T}}$ or peak inspiratory pressure and/or breathing frequency while keeping blood $\mathrm{P}_{\mathrm{CO}_{2}}$ within the normal range. All of these parameters have been shown to directly correlate with severity of BPD. ${ }^{23}$ 


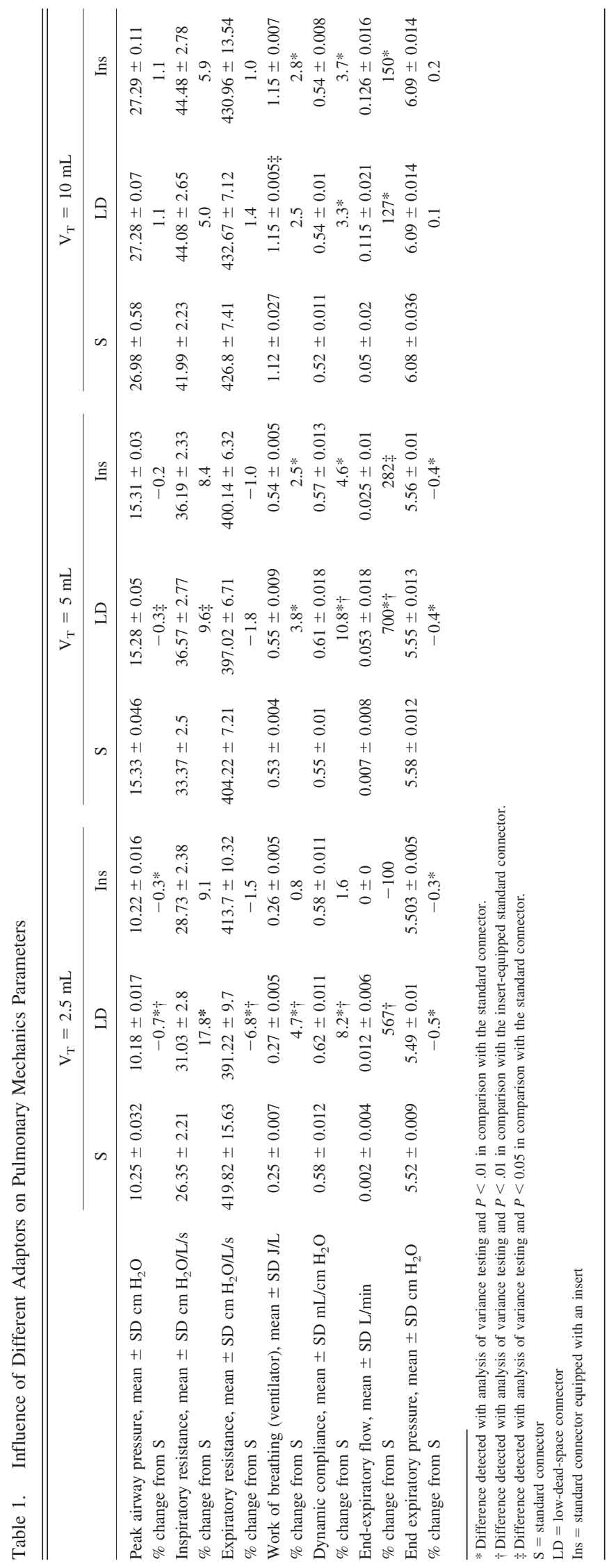




\section{Reduction of Instrumental Dead Space Improves Ventilation}

Since only one specific setup was used, the findings might be applicable only to the specific combination of equipment and parameters that was used in this study (ie, ETT cut to $13 \mathrm{~cm}$, inspiratory time $0.5 \mathrm{~s}$ and breathing frequency 60 breaths/min). Real-life situations would include several other factors that might shape the effect of the instrumental dead-space reduction, like the air leak around an uncuffed ETT, routinely used in neonates. It is also unknown whether the effect would be clinically relevant, even if the findings were confirmed by a study with actual patients being ventilated. However, taking into consideration the anticipated benefits and the lack of likely negative outcomes associated with low-dead-space equipment, it is prudent to choose equipment combinations with lower instrumental dead space whenever possible.

Another finding in this study is the confirmation of complete $\mathrm{CO}_{2}$ elimination out of an artificial lung by ventilation with $\mathrm{V}_{\mathrm{T}}$ below dead space. This phenomenon was previously observed in vivo ${ }^{4}$ and implied in bench tests. ${ }^{21,24}$ This study actually demonstrated that the $\mathrm{CO}_{2}$ elimination was complete in the bench model.

In everyday practice, in-line suction devices and endtidal $\mathrm{CO}_{2}$ measurement connectors could further increase the instrumental dead space. In light of these findings, attempts to eliminate their use where possible and/or to choose combinations with minimal instrumental dead space might result in similar effects. However, clinical studies are required to confirm that using the low-dead-space connector, the insert-equipped standard connector, or any other method of instrumental dead-space reduction produces the expected improvements in the BPD rate or severity.

Both the low-dead-space connector and the insertequipped standard connector are significantly narrower than the standard ETT connector and could increase the resistance of the system. Indeed, using both connectors resulted in increased inspiratory resistance. However, the corresponding effect on ventilator work of breathing was barely significant $(<5 \%)$. Surprisingly, the expiratory resistance had a trend toward reduction and even reached statistical significance with $\mathrm{LD}$ ventilated with $\mathrm{V}_{\mathrm{T}}$ of $2.5 \mathrm{~mL}(6.8 \%$ less). Changes in other parameters either did not reach statistical significance or were of such a low magnitude that one would not expect any clinically relevant effect from these changes.

With the assumption that the standard ETT connector has no resistance at all and the gas flow is always laminar, the addition of the low-dead-space connector or the insertequipped standard connector would add $15 \mathrm{~mm}$ (low-deadspace connector) or $20 \mathrm{~mm}$ (insert-equipped standard connector) to the length of the ETT, which is usually cut to no less than $10 \mathrm{~cm}$. Since the resistance of a tube is directly proportional to its length, the addition of low-dead-space connectors would be capable of increasing resistance by no more than $20 \%$. In the described experiment, the ETT was cut to $13 \mathrm{~cm}$, so the highest expected addition to the resistance would be $15.4 \%$ for the insert-equipped standard connector and $11.5 \%$ for the low-dead-space connector. The observed maximal increase in inspiratory resistance was on the order of these expected values: $9.06 \%$ for the insert-equipped standard connector and $17.79 \%$ for the low-dead-space connector. However, the observation of decreased expiratory resistance contradicts this theory. This might be because the gas flow within many parts of the circuit is not laminar, but turbulent. This turbulence increases resistance to the gas flow. Therefore, one could speculate that the observed differences between the theoretically expected and measured resistances are due to changes in the turbulence of flow with the introduction of the new connectors.

\section{Conclusions}

In summary, the insert-equipped standard connector and the low-dead-space connector somewhat increase the total inspiratory resistance of the system and ventilator work of breathing but are unlikely to affect patients on full ventilatory support, since the ventilator would compensate for the changes. The lack of any observed increase in expiratory resistance indicates that expiration time would not be affected. Thus, one should not expect an increase in the risk for auto-PEEP and breath-stacking.

Increased inspiratory resistance with a corresponding increase of work of breathing, although relatively small $(<5 \%)$, could affect patients during weaning from the ventilator. The significance of this effect should be further explored in an animal model and/or in clinical situations.

Although clinical use of the proposed insert may be not practical, it shows the importance of further work toward reducing instrumental dead space while ventilating an extremely small patient, like an extremely low-birth weight infant. It is also important to consider that the low-deadspace connector has been reported to be incompatible with some devices. ${ }^{25}$

The best known prevention for BPD is reducing the time spent on the ventilator. In intubated infants, multiple approaches to minimize ventilator-induced lung trauma have been described, but there is currently no universally effective and safe measure for BPD prevention or therapy. At the same time, BPD is a major problem affecting many infants.

Any method that reduces the incidence or severity of BPD by even a small fraction could lead to a significant number of prevented and/or attenuated cases. This study has provided experimental evidence that supports using a simple method to decrease instrumental dead space, which allows for reduced ventilator settings without compromising $\mathrm{CO}_{2}$ elimination. Pending confirmation in the clinical setting, using this method of instrumental dead-space re- 


\section{Reduction of Instrumental Dead Space Improves Ventilation}

duction should be expected to translate into a lower incidence and/or severity of BPD.

\section{ACKNOWLEDGMENTS}

I thank Mr T Spivey for manufacturing the insert, Mrs L Kotcharova for help in building and running the model, and Mrs K Kyler and Mrs A Bubenshchikova for help in preparation of the manuscript and figures.

\section{REFERENCES}

1. Goldsmith JP, Karotkin EH. Assisted ventilation of the neonate. Philadelphia: Saunders; 2011:476.

2. Greenough A, Premkumar M, Patel D. Ventilatory strategies for the extremely premature infant. Paediatr Anaesth 2008;18(5):371-377.

3. Nolte S. Respiratory death space and ventilation of newborn infants. Klin Padiatr 1992;204(5):368-372.

4. Nassabeh-Montazami S, Abubakar KM, Keszler M. The impact of instrumental dead-space in volume-targeted ventilation of the extremely low birth weight (ELBW) infant. Pediatr Pulmonol 2009; 44(2):128-133.

5. Carlo WA, Stark AR, Wright LL, Tyson JE, Papile LA, Shankaran $\mathrm{S}$, et al. Minimal ventilation to prevent bronchopulmonary dysplasia in extremely-low-birth-weight infants. J Pediatr 2002;141(3):370374.

6. Miller JD, Carlo WA. Safety and effectiveness of permissive hypercapnia in the preterm infant. Curr Opin Pediatr 2007;19(2):142-144.

7. Kaiser JR, Gauss CH, Pont MM, Williams DK. Hypercapnia during the first 3 days of life is associated with severe intraventricular hemorrhage in very low birth weight infants. J Perinatol 2006;26(5): 279-285.

8. Dassieu G, Brochard L, Benani M, Avenel S, Danan C. Continuous tracheal gas insufflation in preterm infants with hyaline membrane disease. A prospective randomized trial. Am J Respir Crit Care Med 2000;162(3 Pt 1):826-831.

9. Estay A, Claure N, D’Ugard C, Organero R, Bancalari E. Effects of instrumental dead space reduction during weaning from synchronized ventilation in preterm infants. J Perinatol 2010;30(7):479-483.

10. Wald M, Kalous P, Lawrenz K, Jeitler V, Weninger M, Kirchner L. Dead-space washout by split-flow ventilation. A new method to reduce ventilation needs in premature infants. Intensive Care Med 2005;31(5):674-679.

11. Kolobow T, Berra L, DeMarchi L, Aly H. Ultrathin-wall, two-stage, twin endotracheal tube: a tracheal tube with minimal resistance and minimal dead space for use in newborn and infant patients. Pediatr Crit Care Med 2004;5(4):379-383.

12. Claure N, D'Ugard C, Bancalari E. Elimination of ventilator dead space during synchronized ventilation in premature infants. J Pediatr 2003;143(3):315-320.

13. Lethvall S, Lindgren S, Lundin S, Stenqvist O. Tracheal doublelumen ventilation attenuates hypercapnia and respiratory acidosis in lung injured pigs. Intensive Care Med 2004;30(4):686-692.

14. Chen XN, Wu JC, Geng R, Zhang XP. Experimental study of double-lumen, two-stage endotracheal tube during conventional mechanical ventilation in rabbits. Crit Care Med 1997;25(3):492-495.

15. De Robertis E, Uttman L, Jonson B. Re-inspiration of $\mathrm{CO}_{2}$ from ventilator circuit: effects of circuit flushing and aspiration of dead space up to high respiratory rate. Crit Care 2010;14(2):R73.

16. Terragni PP, Birocco A, Faggiano C, Ranieri VM. Extracorporeal CO2 removal. Contrib Nephrol 2010;165:185-196.

17. NRP Neonatal Resuscitation Textbook 6th Edition. American Academy of Pediatrics; 2011:165.

18. Cools F, Offringa M, Askie LM. Elective high frequency oscillatory ventilation versus conventional ventilation for acute pulmonary dysfunction in preterm infants. Cochrane Database Syst Rev 2015;(3): CD000104.

19. Beran AV. Coupler for respiratory apparatus. US Patent D245921 S. September 27, 1977.

20. Lethvall S, Søndergaard S, Kárason S, Lundin S, Stenqvist O. Deadspace reduction and tracheal pressure measurements using a coaxial inner tube in an endotracheal tube. Intensive Care Med 2002;28(8): 1042-1048.

21. Wald M, Jeitler V, Lawrenz K, Weninger M, Kirchner L. Effect of the Y-piece of the ventilation circuit on ventilation requirements in extremely low birth weight infants. Intensive Care Med 2005;31(8): 1095-1100.

22. Pollio V, Morgan MH, Warren HL. Vitruvius, the ten books on architecture. Cambridge, MA: Harvard University Press; 1914:253254.

23. Simbruner G, Mittal RA, Smith J, Maritz G, van Rensberg J, Simbruner B, Holzinger A. Effects of duration and amount of lung stretch at biophysical, biochemical, histological, and transcriptional levels in an in vivo rabbit model of mild lung injury. Am J Perinatol 2007;24(3):149-159.

24. Keszler M, Montaner MB, Abubakar K. Effective ventilation at conventional rates with tidal volume below instrumental dead space: a bench study. Arch Dis Child Fetal Neonatal Ed 2012;97(3):F188F192.

25. Haffner ME. Food and Drug Administration warning on dead space in tracheal tubes. Pediatrics 1984;73(3):414.

This article is approved for Continuing Respiratory Care Education credit. For information and to obtain your CRCE

(free to AARC members) visit www.rcjournal.com 